\title{
Intrauterine foreign body presenting as a rectal bezoar and causing chronic diarrhea
}

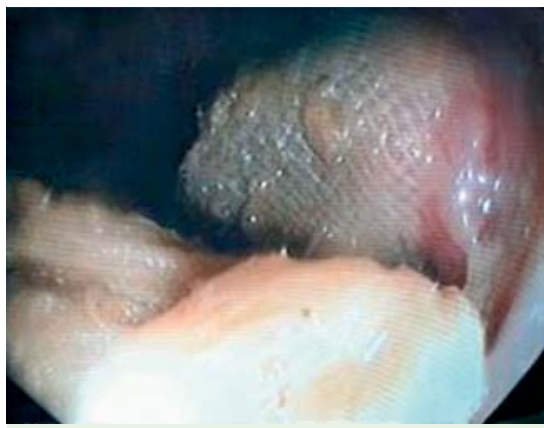

Fig. 1 Colonoscopic view in a 32-year-old woman with lower abdominal pain and diarrhea 7 months after a Caesarean section showing a rectal bezoar with a mesh-like appearance consistent with an embedded swab.

A 32-year-old woman presented to us with a 7-month history of chronic low grade lower abdominal pain and diarrhea of large-bowel type, which had begun after the delivery of her baby by Caesarean section. She had been treated with antibiotics, probiotics, and anticholinergic drugs. A colonoscopy was performed, which showed what appeared to be a large bandage that was completely embedded in the rectal mucosa and could not be removed with foreign-body removal forceps ( Fig.1). An ultrasound was performed, which revealed that anteriorly the bandage was embedded in the uterine wall and posteriorly it was eroding the rectal wall ( $\bullet$ Fig. 2).

The patient then informed us that during her Caesarean section a swab had gone missing. Postoperatively a thorough search had been undertaken using ultrasonography but nothing abnormal had been identified. She developed diarrhea and vague low grade lower abdominal pain 1 week later and was treated initially for infective diarrhea and then as irritable bowel syndrome (IBS).

After the colonoscopic discovery of the missing swab, surgical removal of the foreign body and repair of the tear was undertaken at our institute. She was well on discharge and at a follow-up appointment 2 weeks later.

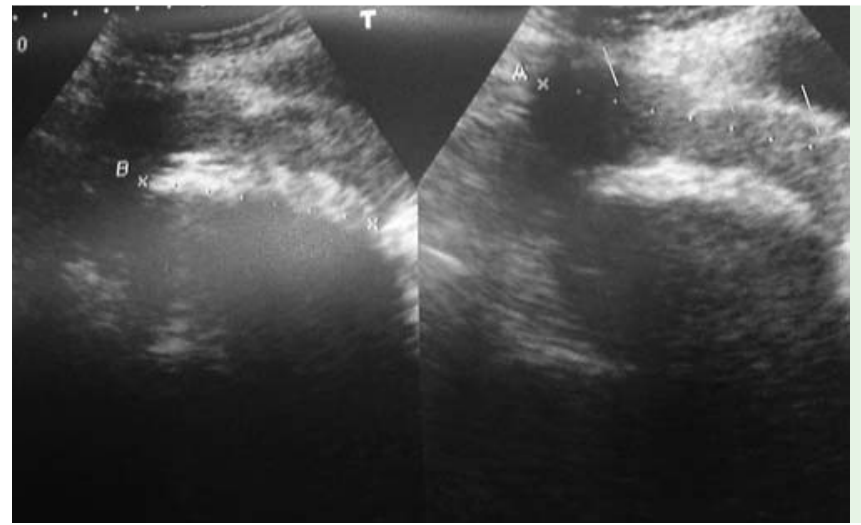

Fig. 2 Ultrasound apperance showing the extent of the rectal bezoar, which anteriorly was embedded in the uterine wall.

The term "bezoar" originates from the Arabic term badzehar, meaning "antidote." Bezoars most commonly form in stomach, but may occur in the small intestine and, rarely, in the colon or rectum [1]. Bezoars include phytobezoars (composed of indigestible food materials such as seeds and pips), trichobezoars (composed of hair), lactobezoars (composed of lactose), and pharmacobezoars (composed of medications). Common clinical manifestations include nausea, vomiting, anorexia, weight loss, constipation, and obstipation. Possible complications of bezoars include obstruction, ulceration, hemorrhage, and perforation [2].

There are rare cases reported in the literature of rectal bezoars being caused by watermelon seeds, sunflower seeds, and invading plant materials [3-5]. However, there are no previous reports of an iatrogenic intrauterine foreign body that has eroded into the rectal wall presenting as chronic diarrhea and being diagnosed colonoscopically as a rectal bezoar.

Endoscopy_UCTN_Code_CCL_1AD_2AJ

Competing interests: None

\section{Jayant Ghosh, Sundeep Goyal, Sangey Lamtha, Pankaj Kaushik, Manish Tripathi, Sunit Shukla, Vinod Dixit, A. K. Jain}

Department of Gastroenterology, Institute of Medical Sciences, Banaras Hindu University Varanasi, India
References

1 Minty B, Kelly L. Rectal bezoars in children. Can Med Assoc J 2010; 182: E532

2 Manne JR, Rangu VM, Motapothula UMR et al. A crunching colon: rectal bezoar caused by pumpkin seed consumption. Clinic Med Res 2012; 10: 75 - 77

3 Britton PN, Polon M. A case of impacted watermelon seed rectal bezoar in a 12-year-old girl. J Paediatr Child Health 2011; 47: 68 -69

4 Lane RD, Schunk JE. Sunflower rectal bezoar presenting with an acute abdomen in a 3-year-old child. Pediatr Emerg Care 2010; 26: 662-664

5 Mahjoub F, Kalantari M, Tabarzan N et al. Invading plant material appearing as a colonic tumoural mass in a four-year-old girl. Trop Doct 2009; 39: 253-254

Bibliography

DOI http://dx.doi.org/

10.1055/s-0033-1344867

Endoscopy 2013; 45: E399

(c) Georg Thieme Verlag KG

Stuttgart · New York

ISSN 0013-726X

Corresponding author

Jayant Ghosh, MD

Institute of Medical Sciences - Department

of Gastroenterology

Banaras Hindu University

Varanasi

Uttar Pradesh 221005

India

Fax: $+91-542-2367568$

drjayantkg@yahoo.co.uk 